J.Lake Sci. (湖泊科学), 2016, 28(1): 124-131

DOI 10. 18307/2016. 0114

(C) 2016 by Journal of Lake Sciences

\title{
湖泊湿地的水质净化效应——太湖三山湿地为例
}

\author{
王 雁, 黄佳聪, 间人华, 高俊峰** \\ (中国科学院南京地理与湖泊研究所, 中国科学院流域地理学重点实验室, 南京 210008)
}

\begin{abstract}
摘 要: 为了解湖泊湿地的水质净化效果, 以太湖三山湿地为研究对象, 综合利用遥感、GIS 技术、现场水质监测、实验室 分析和模型模拟等方法, 分析三山湿地对污染物的拦截净化效果, 进而探讨湖泊湿地对水体氮、磷污染物的削减渠道及 其贡献率. 结果表明三山湿地对太湖水体和三山岛生活污水均有明显净化效果. 2014 年三山湿地的总氮 (TN)、总磷( TP) 输人通量分别为 549.45 和 $19.4 \mathrm{t}$, 通过水草打捞/收割分别去除 20.99 和 $4.52 \mathrm{t}$, 湿地水体内 TN 、 TP 变化量分别为 528.46 和 $14.88 \mathrm{t}$, 这部分营养盐输出途径包括沉积到底泥、降解转化、水体交换等.湿地的 TN、TP 拦截能力分别为 2723.56 和 $102.48 \mathrm{~kg} /\left(\mathrm{hm}^{2} \cdot \mathrm{a}\right)$. 水生植物收割打捞与底泥疏浚是提高湿地水质净化能力的有效措施. 水动力模拟结果显示, 三山湿 地建成后使附近水域水体流向发生变化,流速减小,对湿地内水质产生多方面的作用.
\end{abstract}

关键词: 湖泊湿地; 三山湿地;太湖;水质净化;氮; 磷; 水动力

\section{Nutrient removal efficiency of lake wetlands: A case study of Sanshan Wetland in Lake Taihu, eastern China}

WANG Yan, HUANG Jiacong, YAN Renhua \& GAO Junfeng **

( Key Laboratory of Watershed Geographic Sciences, Nanjing Institute of Geography and Limnology, Chinese Academy of Sciences, Nanjing 210008, P.R.China)

\begin{abstract}
To understand the function of lake wetlands in nutrient removal efficiency, Sanshan Wetland in Lake Taihu was selected as the study region. Remote sensing, GIS techniques, field investigation, chemical analysis and hydro-dynamical simulation were integrated to analyze the effects of nitrogen and phosphorus nutrient retention of wetland in this study. Various forms of nitrogen and phosphorus in the Sanshan Wetland were analyzed. In 2014, the input of total nitrogen( TN) and total phosphorus ( TP) were 549.45 $\mathrm{t}$ and $19.4 \mathrm{t}$, respectively. About $20.99 \mathrm{t} \mathrm{TN}$ and $4.52 \mathrm{t}$ TP were removed by emerged plants harvest and floating plants salvages. Changes of TN and TP in Sanshan Wetland were 528.46 and $14.88 \mathrm{t}$ during the year, respectively. Ways of the nutrients output included several processes of phosphorus sunking, depositing, degradating and exchanging between the Sanshan Wetland and Lake Taihu. The wetland captures of TN and TP were 2723.56 and $102.48 \mathrm{~kg} /$ ( ha $\cdot$ a), respectively. The sediment dredging and plant harvesting and refloating are good ways to improve the water quality in Sanshan Wetland. Hydrodynamic simulation results show that due to the construction of Sanshan Wetland, the flow directions have changed and the velocity currents reduced.
\end{abstract}

Keywords: Lake wetlands; Sanshan Wetland; Lake Taihu; nutrient removal; nitrogen; phosphorus; hydrodynamic

湖泊是湿地的一种类型,包括湖泊水体本身和滨岸带周期性淹水区域,也称湖泊湿地 ${ }^{[1]}$. 湖泊湿地的水 质净化是指湿地生态系统通过自然生态过程及物质循环作用,将水体中氮、磷等富营养化物质予以吸收、转 化、再分配, 使水体得以净化 ${ }^{[2]}$. 以湖泊湿地对陆源物质的截留作用为例, 当河流携带的物质进入湖泊湿地 后,由于水动力减弱,加之水生植物的拦截,重金属、营养盐和泥沙等在此汇聚, 受到机械吸附、过滤和沉积 作用,并发生离子交换、络合、水解和微生物分解及植物根系吸收等生物化学作用,通过生物沉积和生物同 化输出,保护自身水体,并对过往的水体进行水质净化 ${ }^{[3]}$.近年来, 由于水体污染和富营养化现象日趋严重,

* 国家水体污染控制与治理科技重大专项 (2012ZX07501-01,2012ZX07506-01) 和水利部太湖流域管理局项目联合 资助.2015-02-04 收稿; $2015-05-29$ 收修改稿.王雁( 1983 ), 女,博士;E-mail: ywang@ niglas.ac.cn.

** 通信作者;E-mail: gaojunf@ niglas.ac.cn. 
湿地生态系统在维持氮、磷等元素的生物地球化学循环、净化水质等方面的作用越来越受到关注 ${ }^{[4-5]}$. 国内外 在人工湿地污水处理技术 ${ }^{[6]}$ 、沟塘湿地控制农田面源污染 ${ }^{[7]}$ 、流域湿地养分截留 ${ }^{[8]}$ 和重金属拦截功能 ${ }^{[9]}$ 等 方面开展了大量工作,结果表明流域内一定面积和数量的湿地能够通过沉积、过滤、吸附、生物化学转化等 过程减少污染物, 从而达到改善水质的目标 ${ }^{[10-12]}$. 对天目湖湿地 ${ }^{[8]}$ 、龙感湖湿地 ${ }^{[9]}$ 、银川黄河湿地公园 ${ }^{[12]}$ 等 湖泊湿地研究表明,湿地对人湖污染具有明显的拦截和净化作用. 然而随着富营养化问题日趋严重,湖泊水 体可能逐渐由氮、磷的汇转变成向周围湿地输出的源. 目前对衡量湖泊湿地水质净化功能的研究, 多采用通 过比较进水断面和出水断面水体氮、磷浓度差来表述湿地的水质净化功能. 对于开放性、无明显边界的天然 湖泊湿地与水体之间氮、磷生物地化过程的研究相对较少, 有关湿地对水质净化功能的有效性还需进一步 加强 ${ }^{[13]}$. 开展氮、磷元素在富营养化湖泊水体与湖泊湿地间的迁移规律研究有助于阐明湖泊湿地对富营养 化湖泊的生态效应,为湖泊湿地优化管理提供参考数据.

近年来太湖水体富营养化程度日益严重, 湿地的净化效果也受到广泛关注 ${ }^{[14]}$.三山岛是位于太湖西南 的湖中岛, 岛上将天然滩涂改造为人工湿地, 建成三山岛国家湿地公园, 发挥了三山岛的生态屏障和太湖水 源涵养作用, 为湖中岛屿湿地公园建设起到示范作用, 但目前关于三山岛具体的净化能力还尚未研究. 如何 定量评估三山湿地的截留净化效果? 对其他大型淡水湖泊湿地工程有何借鉴? 基于以上科学问题和现实 问题, 本文拟通过计算三山湿地氮、磷输人输出通量, 分析湖泊湿地对不同来源的氮、磷污染物的拦截净化 效果, 为太湖三山湿地污染控制管理提供依据,也为其他淡水湖泊湿地工程设计及运行管理提供参考.

\section{1 研究区域概况}

三山湿地 $\left(31^{\circ} 1^{\prime} \sim 31^{\circ} 2^{\prime} \mathrm{N}, 120^{\circ} 15^{\prime} \sim 120^{\circ} 18^{\prime} \mathrm{E}\right)$ 位于苏州市西南 $50 \mathrm{~km}$ 的太湖之中, 是由岛屿及毗邻水域构 成的一个湿地公园, 面积 $2.8 \mathrm{~km}^{2}$. 多年平均气温 $15.7 \sim 16.0^{\circ} \mathrm{C}$, 降雨量 $1100 \sim 1400 \mathrm{~mm}$. 常水位 $3.10 \mathrm{~m}$, 年变幅1 m 左右,平均水深约 $2.5 \mathrm{~m}$.

\section{2 研究方法}

\section{1 监测点布设与采样分析}

三山湿地按建设时间分为湿地一区和湿地二区 2 个区域 (图 1、表 1). 根据三山湿地建设周期和水生植 物分布特征, 按照湿地净化能力评估要求, 在湿地水体内从沿岸到开敞湖面的方向, 设置监测点 $1^{\#} \sim 6^{\#}$, 同时 为试验深水对污染物的净化能力, 在湿地一区西南部相对封闭的区域设置监测点 $7^{\#}$, 该区域水深为 $5 \mathrm{~m}$ 左 右,水草分布较少,无污染源排入 (表 2).

为反映三山湿地不同季节的水质变化过程, 2014 年选择不同的水生植物生长期进行现场水质监测与采 样, 分别为春季生长初期 ( 5 月 20 日)、夏季生长旺盛期 ( 8 月 20 日)、秋季衰败期 (10 月 16 日). 为避免降雨 对湿地水质的影响, 现场工作均在晴天进行. 根据氮、磷在水体中的存在形式, 监测指标分为溶解性和颗粒态 两类, 即: 总氮 $(\mathrm{TN})$ 包括溶解性氮 $(\mathrm{DN})$ 和颗粒态氮 $(\mathrm{PN})(\mathrm{PN}=\mathrm{TN}-\mathrm{DN})$, 总磷 ( TP ) 包括溶解性磷 (DP) 和 颗粒态磷 ( PP) ( PP = TP-DP). 现场采集水样和底泥带回实验室分析, 水样一部分直接用于测定 TN 和 TP, 另 一部分经 $0.45 \mu \mathrm{m}$ 滤膜过滤后测定 DN 和 DP. 底泥样品经离心处理 (4200 转/ $\min , 20 \mathrm{~min}$ ), 取上清液过滤后 测定底泥间隙水 DN 和 DP 浓度.DP 和 TP 浓度采用钿酸铵分光光度法 (HJ 670-2013) 测定, DN 和 TN 浓度 采用盐酸䒬乙二胺分光光度法 (HJ 668-2013) 测定. 用水草定量夹采集 $1 \mathrm{~m}^{2}$ 内的水生高等植物, 现场进行种 类鉴定及生物量测定.三山湿地的水生高等植物类型多样, 湿地中水生植物多为本地水生生物物种, 可以较 好地体现天然湖泊湿地的状态. 包括挺水植物、浮叶植物与沉水植物, 其中挺水植物以荠草 (Zizania latifolia)、荷花 (Nelumbo nucifera)、香蒲 (Typha orientalis Presl) 与芦苇 (Phragmites communis Trin) 分布最为广 泛,沉水植物与浮叶植物主要分布在湿地内部水体, 以野菱 (Trapa incisa)、杏菜 (Nymphoides peltata)、轮叶黑 藻 (Hydrilla verticillata) 和狐尾藻 (Myriophyllum verticillatum) 为主. 水生植物生长期为春、夏、初秋 3 季, 生长 过程受人为干扰较小,采用 2014 年 5 月 21 日的调查结果代表春季的生物量水平.

\section{2 三山湿地 TN、TP 拦截效应评估方法}

三山湿地的水体主要来自太湖和三山岛,湿地 TN、TP 拦截效应包括对太湖水体和三山岛上污水的拦 


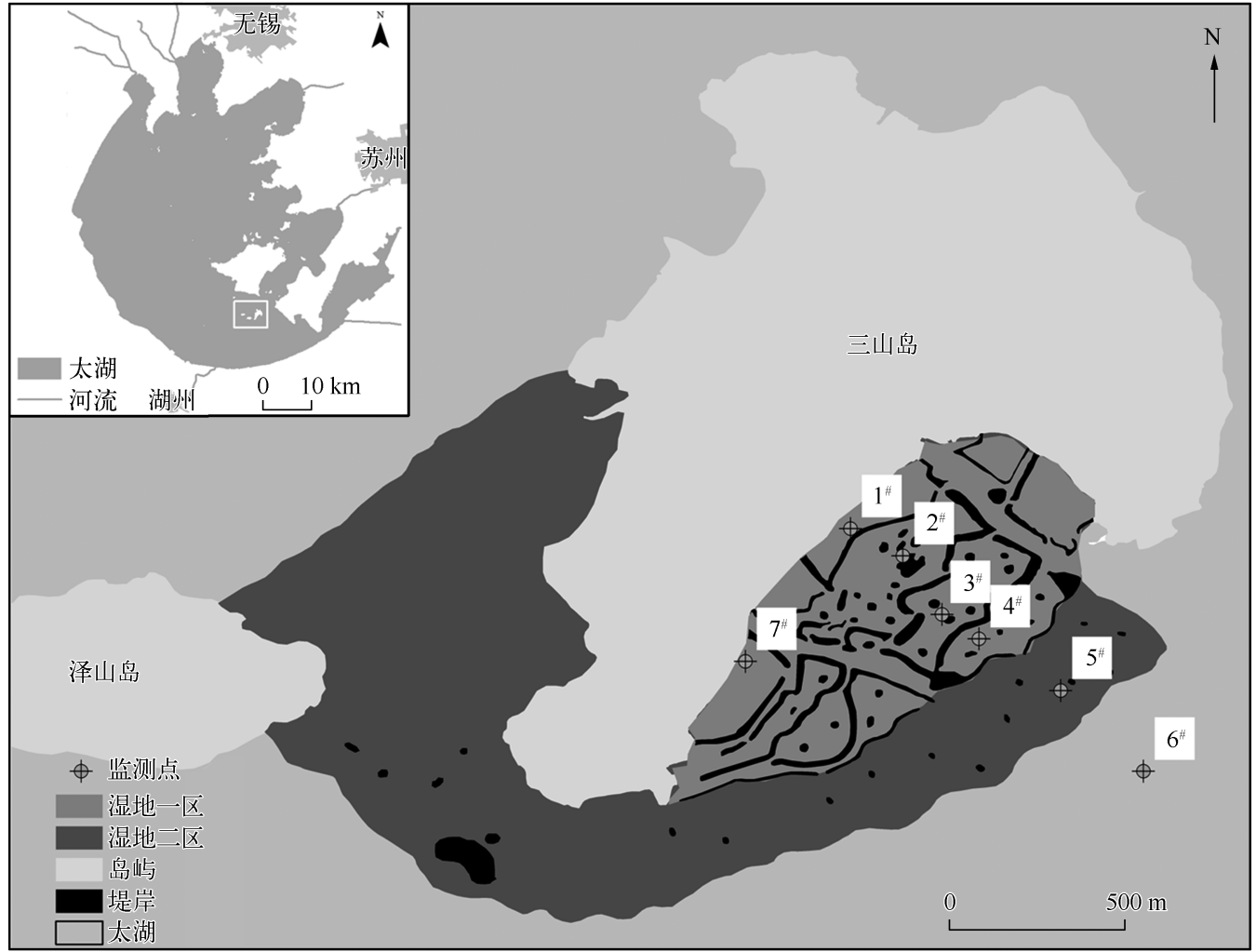

图 1 三山湿地的位置与监测点分布

Fig. 1 Location of Sanshan Wetland and sampling sites

截.2013 年湿地二区建成, 与太湖水体之间被大量堤岸隔离, 湿地内部形成相对封闭的水域, 仅有少量水体 可以通过堤岸开口与外部的太湖交换, 这部分经过湿地净化后输出的水体选取距离堤岸出口最近的 $5^{\#}$ 监测 点代表, 湿地外部未经净化的太湖水体用堤岸外的 $6^{\#}$ 监测点代表.三山岛上污水通过管网收集后进人岛上污 水处理厂, 处理后排人湿地, 排污口位于岛上南部 $1^{\#}$ 监测点附近.

\section{表 1 三山湿地工程状况}

Tab.1 Present condition of Sanshan Wetland project

\begin{tabular}{cccccc}
\hline 区域 & 始建年份 & 面积 $\left(\times 10^{4} \mathrm{~m}^{2}\right)$ & 堤岸分布 & 植物组成 & 平均生物量 $/\left(\mathrm{kg} / \mathrm{m}^{2}\right)$ \\
\hline 湿地一区 & 2008 & 43.48 & 区内均匀分布 & 大量挺水和沉水植物 & 5.9 \\
湿地二区 & 2013 & 119.62 & 区域四周分布 & 少量挺水和沉水植物 & 3.0 \\
\hline
\end{tabular}

表 2 监测点及水体植被特征

Tab.2 Characteristics of vegetation in the sampling sites

\begin{tabular}{ccccc}
\hline 监测点 & 代表区域 & 水生植物类型及分布状况 & 生物量 $/\left(\mathrm{kg} / \mathrm{m}^{2}\right)$ & 位置 \\
\hline $1^{\#}$ & 水生植物密集区 & 密集的挺水植物、浮叶植物与沉水植物 & 7.0 & 湿地一区 \\
$2^{\#}$ & 浮叶植物稀疏区 & 密集的沉水植物和较稀疏的浮叶植物 & 5.8 & 湿地一区 \\
$3^{\#}$ & 沉水植物密集区 & 以沉水植物为主 & 6.0 & 湿地一区 \\
$4^{\#}$ & 沉水植物稀疏区 & 有少量的沉水植物,无浮叶植物 & 4.8 & 湿地一区 \\
$5^{\#}$ & 削弱风浪区 & 水生植物数量较少,呈斑块状分布 & 3.0 & 湿地二区 \\
$6^{\#}$ & 敞水区 & 仅有极少的水草,无挺水植物 & 0 & 湿地二外围 \\
$7^{\#}$ & 深水区 & 相对封闭,水草分布较少,无污染源排人 & 0 & 湿地一区西南 \\
\hline
\end{tabular}


2.2.1 三山湿地对太湖水体 TN、TP 的拦截效应 湿地对太湖水体年度 TN、TP 的拦截作用由太湖水体与湿 地 TN、TP 的差来计算:

$$
\varphi_{\mathrm{N}(\mathrm{P}) \_ \text {Tai }}=V_{\mathrm{W}}\left(C_{\mathrm{N}(\mathrm{P}) \_ \text {Tai }}-C_{\mathrm{N}(\mathrm{P}) \_\mathrm{W}}\right)
$$

三山湿地对太湖水体 $\mathrm{TN}(\mathrm{TP})$ 的拦截率 $R_{\mathrm{N}(\mathrm{P}) \_\mathrm{Tai}}$ 可根据式(2) 计算求得:

$$
R_{\mathrm{N}(\mathrm{P}) \_ \text {Tai }}=\left[\varphi_{\mathrm{N}(\mathrm{P}) \_ \text {Tai }} /\left(V_{\mathrm{W}} \cdot C_{\mathrm{N}(\mathrm{P}) \_ \text {Tai }}\right)\right] \times 100 \%
$$

式中, $\varphi_{\mathrm{N}(\mathrm{P}) \_\mathrm{Tai}}$ 为 $t$ 时间内湿地吸收太湖水体的 $\mathrm{TN}(\mathrm{TP})$ 总量, $V_{\mathrm{W}}$ 为湿地总水量, $C_{\mathrm{N}(\mathrm{P}) \_\mathrm{Tai}} C_{\mathrm{N}(\mathrm{P}) \_\mathrm{W}}$ 分别为湿地 外围、湿地内部水体的 TN $(\mathrm{TP})$ 浓度.

$V_{\mathrm{W}}$ 可通过 GIS 地形分析, 由式(3) 计算获得:

$$
V_{\mathrm{w}}=\sum_{i=1}^{n}\left(S \cdot h_{i}\right)
$$

式中, $S$ 为划分湿地网格单元的面积, $h_{i}$ 为网格 $i$ 的水深.

2.2.2 三山湿地对三山岛污水 TN、TP 的拦截效应 湿地对三山岛污水的 TN(TP) 拦截总量计算公式为:

$$
\varphi_{\mathrm{N}(\mathrm{P}) \_ \text {Sew }}=V_{\mathrm{S}}\left(C_{\mathrm{N}(\mathrm{P})_{-} \text {Sew }}-C_{\mathrm{N}(\mathrm{P}) \_\mathrm{W}}\right)
$$

三山湿地对三山岛污水 $\mathrm{TN}(\mathrm{TP})$ 的拦截率 $R_{\mathrm{N}(\mathrm{P}) \_ \text {Sew }}$ 为:

$$
R_{\mathrm{N}(\mathrm{P}) \_ \text {Sew }}=\left[\varphi_{\mathrm{N}(\mathrm{P}) \_ \text {Sew }} /\left(V_{\mathrm{W}} \cdot C_{\mathrm{N}(\mathrm{P}) \_ \text {Sew }}\right)\right] \times 100 \%
$$

式中, $V_{\mathrm{S}}$ 为三山岛的年度污水处理量, $\varphi_{\mathrm{N}(\mathrm{P}) \_ \text {Sew }}$ 为湿地年度吸收污水的 $\mathrm{TN}(\mathrm{TP}) ; C_{\mathrm{N}(\mathrm{P}) \_\mathrm{W}}$ 为湿地内部水体的 $\mathrm{TN}$ $(\mathrm{TP})$ 浓度, $C_{\mathrm{N}(\mathrm{P}) \_ \text {Sew }}$ 为污水出水口水体的 $\mathrm{TN}(\mathrm{TP})$ 浓度, 通过对污水出水口样品分析获取.

\section{3 水动力条件模拟}

水动力条件是水体物质输移与颗粒物沉降的重要影响因素, 模拟湿地建设对水动力条件的影响是湿地 水质净化能力评价的重要环节.本研究采用准三维湖泊水动力模型模拟三山湿地水动力状况, 模型以二维水 动力模型为基础, 假定水平流速在垂直方向上的分布曲线呈近似二次抛物线, 并根据这一分布曲线, 结合二 维水动力模型获得的平均流速, 计算不同深度的水平流速 ${ }^{[15]}$. 该模型已应用于工程建设的环境影响评价、湖 泊蓝藻水华模拟、湖泊水环境过程模拟、通江湖泊水环境模拟等研究和工程生态环境影响评价领域,模型原 理及参数详见文献 [16-20].

水动力模型的模拟条件设置详细说明如下:

初始条件:湖体网格单元的初始流速为 $0 \mathrm{~m} / \mathrm{s}$, 初始水位为 $3 \mathrm{~m}$.

边界条件: 太湖平均水域面积 $2338 \mathrm{~km}^{2}$, 现有进出口河道 228 条, 据 2010 年资料, 环太湖河流人湖水量 为 $118.81 \times 10^{8} \mathrm{~m}^{3}$, 出湖水量为 $110.06 \times 10^{8} \mathrm{~m}^{3[21]}$. 与太湖的湖体面积相比, 出人河流对流场的影响较小, 本研 究区域集中在三山湿地周边水域, 与出入湖河流距离较远, 因此不考虑出入湖河流的边界条件.

时间步长: 时间步长为 $2 \mathrm{~s}$.

模拟时长: 因在连续 $3 \mathrm{~d}$ 的定常风作用下,湖体流场可达到稳定状态,模拟时长为 $3 \mathrm{~d}$.

模拟情景: 太湖自然条件复杂, 风力和风向组合很多, 本研究只考虑盛行风向下的情景 ${ }^{[22-23]}$. 根据中国科 学院南京地理与湖泊研究所太湖湖泊生态系统观测研究站多年观测资料, 太湖的年平均风速为 $3.6 \mathrm{~m} / \mathrm{s}$, 冬 季盛行西北风,夏季盛行东南风. 为模拟湿地建设前后周围水域的水动力条件变化, 按照有无湿地分布和盛 行风向的组合设置 4 种模拟情景 (表 3 ). 湿地建设前后的基础信息根据遥感卫星影像解译获得.

网格剖分:研究区划分为 $50 \mathrm{~m} \times 50 \mathrm{~m}$ 的网格单元.

\section{3 结果与讨论}

\section{1 三山湿地水体 TN、TP 分布的空间和季节特征}

各监测点水体 $\mathrm{TN}$ 组成以 $\mathrm{DN}$ 为主, $\mathrm{PN}$ 在 $\mathrm{TN}$ 中所占比重不大, $\mathrm{TN}$ 浓度在空间分布上沿 $1^{\#} \sim 6^{\#}$ 监测点呈 现微弱上升趋势. 监测点 $1^{\#} \sim 3^{\#}$ 的 TN 浓度年内平均值差异不大 $(0.91 \sim 1.09 \mathrm{mg} / \mathrm{L}), 6^{\#}$ 监测点的 TN 浓度 
$(1.57 \mathrm{mg} / \mathrm{L})$ 略高于其它监测点. $1^{\#} \sim 6^{\#}$ 监测点的水深较浅, 监测表明分层水体的 N、P 浓度差异很小, 本研究 各监测点均作为垂向均匀水体处理. 深水区 $7^{\#}$ 监测点的 PN 浓度 $(0.09 \mathrm{mg} / \mathrm{L})$ 显著低于其它监测点 $(0.21 \sim$ $0.39 \mathrm{mg} / \mathrm{L})$, 由于深水区 $7^{\#}$ 监测点位于相对封闭水域, 水动力环境较稳定, 相对于其他监测点为 PN 提供了 良好的沉降条件. 从季节上看, 春、夏两季水体中 TN 浓度较低, 由于夏季温度较高, 水生植物生长快, 可促进 有机氮降解, 水体中 TN 浓度处于一年中最低值, 特别是 PN 浓度极低. 秋季气温下降, 植物生长停滞, 微生物 活性降低, 水生植物衰败分解过程分泌的代谢产物及残枝败叶的腐烂物质也会增加水体中的 TN 浓度, 所以 导致秋季 PN 和 DN 浓度均显著高于春、夏 2 季 (图 2a).

表 3 水动力条件变化模拟情景设置

Tab.3 Scenarios simulation for hydrodynamic condition

\begin{tabular}{cccc}
\hline 情景 & 湿地分布状况 & 风力及盛行风向 & 影像日期 \\
\hline 1 & 无湿地分布 & $3.6 \mathrm{~m} / \mathrm{s}$ 东南风 & 2004 年 10 月 24 日 \\
2 & 无湿地分布 & $3.6 \mathrm{~m} / \mathrm{s}$ 西北风 & 2004 年 10 月 24 日 \\
3 & 已建成湿地一区和湿地二区 & $3.6 \mathrm{~m} / \mathrm{s}$ 东南风 & 2013 年 11 月 8 日 \\
4 & 已建成湿地一区和湿地二区 & $3.6 \mathrm{~m} / \mathrm{s}$ 西北风 & 2013 年 11 月 8 日 \\
\hline
\end{tabular}

$1^{\#} 、 2^{\#}$ 监测点的 TP 、PP 浓度年内平均值略高于 $3^{\#} \sim 5^{\#}$ 监测点, $3^{\#} \sim 5^{\#}$ 监测点 DP 浓度无显著差异, $6^{\#}$ 监测 点的 $\mathrm{DP}(0.03 \mathrm{mg} / \mathrm{L})$ 及 $\mathrm{PP}(0.04 \mathrm{mg} / \mathrm{L})$ 浓度均高于其它监测点 $(<0.02 \mathrm{mg} / \mathrm{L})$, 深水区 $7^{\#}$ 监测点的 $\mathrm{PP}$ 与 DP 浓度均较低 $(0.01 \mathrm{mg} / \mathrm{L})$. 这是由生活污水排放与水生植物吸收 TP 共同作用的结果, 尽管 $1^{\#} 、 2^{*}$ 监测点离岛 上污水排放口较近, 但水生植物的密度较高, 能够吸收吸附水体的 DP, 因此 DP 浓度在 $1^{\#} 、 2^{\#}$ 监测点与 $3^{\#} 、 4^{\#}$

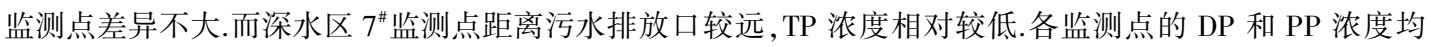
表现出季节差异, 各点秋季 PP 浓度均显著高于春季和夏季, 特别是 $1^{\#} 、 2^{\#}$ 和 $6^{\#}$ 监测点, 而 DP 浓度的季节变 化相对较小. 水生植物的分布和生长状况对磷的去除效果影响很大, 春、夏两季, 水生植物生长迅速, 生物量 大量增加,需要从湿地系统中吸收利用一部分氮、磷营养物.到秋季, 气温下降,生物活性降低,生物吸收过程 相对减缓, 加之水生植物枯萎凋零, 经微生物分解释放植物体内的磷等有机物, 分解的磷以 PP 为主 ${ }^{[22]}$. 因此 秋季 PP 浓度较高, 特别是在水生植物大量分布的区域, 如 $1^{\#} 、 2^{\#}$ 监测点. $6^{\#}$ 监测点秋季 TP 浓度偏高可能与进 水 TP 浓度变化和现场监测的偶然性有关(图 $2 \mathrm{~b}$ ).
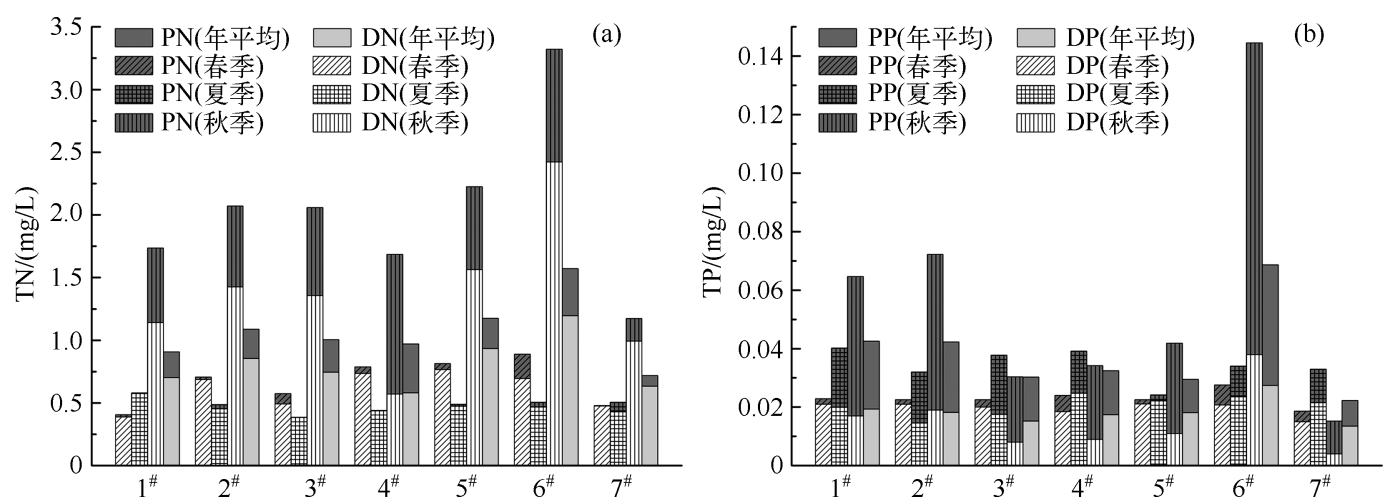

图 22014 年实测三山湿地 TN (a) 和 TP (b) 的空间和季节变化特征

Fig.2 Spatial and seasonal variations of TN(a) and TP(b)concentrations in Sanshan Wetland in 2014

\section{2 三山湿地的 TN、TP 拦截效应}

3.2.1 三山湿地对太湖水体 TN 、 TP 的拦截效应假设湿地建设前内外的氮、磷浓度是一样的,通常采用计算 时段输人和输出氮、磷通量比较的方法来评估湿地氮、磷的净化效应 ${ }^{[12,24-26]}$.湿地一区建成后与太湖水体的 连通区域极小, 且与湿地二区的水量交换极少, 因此湿地对太湖水体的氮、磷拦截作用主要通过湿地二区与 
太湖水体的浓度差计算, 分别用湿地二区堤岸附近的 $5^{\#}$ 监测点和湿地外围的 $6^{\#}$ 监测点的 TN、TP 浓度年内 平均值表示, 已知湿地二区面积 $\left(119.62 \times 10^{4} \mathrm{~m}^{2}\right)$ 、平均水深 $(2.5 \mathrm{~m})$ 、总水量 $\left(299.05 \times 10^{4} \mathrm{~m}^{3}\right)$, 根据公式 $(1)$ 公式(3) 可获得 2014 年度三山湿地对太湖水体的 TN、TP 拦截总量分别为 1.18 和 $0.12 \mathrm{t}$, 拦截率分别为 $25.2 \%$ 和 $56.5 \%$. 按 TN、TP 的形态分, 拦截的 DN 和 DP 分别为 0.78 和 $0.03 \mathrm{t}$, 拦截率分别为 $22 \%$ 和 $34 \%$. 拦截的 PN 和 PP 分别为 0.41 和 $0.09 \mathrm{t}$,拦截率分别为 $36 \%$ 和 $72.2 \%, \mathrm{PP}$ 的拦截率最高.

3.2 .2 三山湿地对三山岛污水 TN、TP 的拦截效应 三山岛上的污染源主要来自生活污水, 来源包括岛上常 年定居的居民和旅游旺季的游客, 根据污水处理厂提供的资料, 岛上生活污水处理量在旅游旺季和淡季分 别约为 500 和 $100 \mathrm{~m}^{3} / \mathrm{d}$. 每年旅游淡季 4 个月, 旺季 8 个月, 则三山岛的年度污水处理量 $\left(V_{\mathrm{S}}\right)$ 约为 $8.65 \times$ $10^{4} \mathrm{~m}^{3}$. 通过污水出水口水样分析获取三山岛生活污水 $\mathrm{TN}(6.26 \mathrm{mg} / \mathrm{L})$ 与 $\mathrm{TP}(0.22 \mathrm{mg} / \mathrm{L})$, 经湿地净化的水

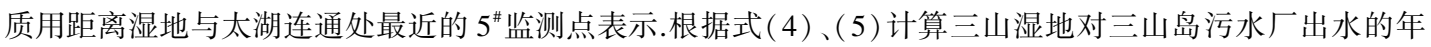
度 $\mathrm{TN} 、 \mathrm{TP}$ 拦截总量分别为 439.77 和 $16.44 \mathrm{t}$, 拦截率分别为 $81.2 \%$ 和 $86.4 \% .2014$ 年三山湿地拦截的来自太 湖水体和三山岛上污水 TN、TP 分别为 440.95 和 $16.55 \mathrm{t}$.

3.2.3 TN、TP 输入与输出通量 三山湿地 $\mathrm{TN} 、 \mathrm{TP}$ 输人来源包括太湖水体输人、岛上生活污水排放和大气沉 降. 据文献 ${ }^{[27-28]}$ 采用太湖流域 TN、TP 大气沉降的经验值, 分别取值 20 和 $1 \mathrm{~kg} /\left(\mathrm{hm}^{2} \cdot \mathrm{a}\right)$, 按照三山湿地总面 积 $161.1 \times 10^{4} \mathrm{~m}^{2}$ 计算获得.

水草打捞与挺水植物收割是氮、磷的输出渠道之一,输出量计算公式为:

$$
\varphi_{\mathrm{N}(\mathrm{P}) \_ \text {Plant }}=\left(p_{\mathrm{SPlant1}} S_{\mathrm{w} 1}+p_{\text {SPlant2 }} S_{\mathrm{w} 2}\right)\left(1-w_{\mathrm{Swater}}\right) w_{\mathrm{SN}(\mathrm{P})}+p_{\text {EPlant }} S_{\text {EPlant }}\left(1-w_{\text {Ewater }}\right) \mathrm{w}_{\mathrm{EN}(\mathrm{P})}
$$

式中, $\varphi_{\mathrm{N}(\mathrm{P}) \_ \text {Plant }}$ 代表沉水植物打捞与挺水植物收割的 TN $(\mathrm{TP})$ 输出通量, $p_{\text {SPlant1 }}$ 和 $p_{\text {SPlant2 }}$ 分别为湿地一区和湿 地二区的沉水植物密度, 现场监测结果分别为 5.9 和 $3 \mathrm{~kg} / \mathrm{m}^{2}, p_{\text {EPlant }}$ 为挺水植物的密度, 监测为 $5.87 \mathrm{~kg} / \mathrm{m}^{2}$. $S_{\mathrm{w} 1}$ 和 $S_{\mathrm{w} 2}$ 分别为湿地一区和湿地二区的面积, $S_{\mathrm{EPlant}}$ 为挺水植物的面积, $w_{\text {Swater }}$ 和 $w_{\text {Ewater }}$ 分别为沉水植物和挺水 植物的含水率, 根据文献 [29] 分别取 $90 \%$ 和 $60 \%, w_{\mathrm{SN}(\mathrm{P})}$ 为烘干后沉水植物含 $\mathrm{N}(\mathrm{P})$ 率, 取 $2 \%(0.5 \%)$, $w_{\mathrm{EN}(\mathrm{P})}$ 为烘干后挺水植物的含 $\mathrm{N}(\mathrm{P})$ 率, 取 $3 \%(0.5 \%)^{[28]}$, 含 $\mathrm{N}(\mathrm{P})$ 率取值为近似值, 实际条件下不同区域的 水生植物有所差异. 得到通过沉水植物打捞输出的 TN、TP 总量分别为 12.31 和 $3.08 \mathrm{t}$. 通过挺水植物收割输 出的 TN 、 TP 总量分别为 8.69 和 1.45 t. TN 、TP 输人总量减去水生植物输出的 TN、TP 总量, 得到湿地内部氮、 磷营养盐的变化量, 这部分营养盐输出途径包括沉降到底泥、被降解或生物转化或留在湿地内部水体中通 过水量交换逐渐输出,三山湿地的 TN 和 TP 输人、输出总量如表 4 所示.

表 42014 年 TN 和 TP 输人、输出三山湿地的总量、途径及比例

Tab.4 The input and output of TN, TP in Sanshan Wetland in 2014

\begin{tabular}{|c|c|c|c|c|c|}
\hline & \multirow{2}{*}{ 途径 } & \multicolumn{2}{|c|}{$\mathrm{TN}$} & \multicolumn{2}{|c|}{$\mathrm{TP}$} \\
\hline & & 总量/t & 比例 $/ \%$ & 总量/t & 比例 $/ \%$ \\
\hline \multirow[t]{4}{*}{ 输人 } & 生活污水 & 541.49 & 98.4 & 19.03 & 97.9 \\
\hline & 湿地外部水体 & 4.70 & 1.0 & 0.21 & 1.3 \\
\hline & 大气沉降 & 3.26 & 0.6 & 0.16 & 0.8 \\
\hline & 输人总量 & 549.45 & 10.0 & 19.40 & 100 \\
\hline \multirow[t]{2}{*}{ 输出 } & 水生植物打捞/收割 & 20.99 & 3.8 & 4.52 & 23.3 \\
\hline & 湿地内营养盐变化量 & 528.46 & 96.2 & 14.88 & 76.7 \\
\hline
\end{tabular}

2014 年通过三山湿地外部的太湖、岛内生活污水和大气沉降输人湿地的 TN 和 TP 量分别为 549.45 和 $19.4 \mathrm{t}$. 其中通过水生植物打捞/收割拦截的 TN 和 TP 量分别为 20.99 和 $4.52 \mathrm{t}$, 湿地内 TN 和 TP 变化量分别 为 528.46 和 $14.88 \mathrm{t}$, 三山湿地对 $\mathrm{TN}$ 的拦截能力为 $2723.56 \mathrm{~kg} /\left(\mathrm{hm}^{2} \cdot \mathrm{a}\right)$, TP 拦截能力为 $102.48 \mathrm{~kg} /\left(\mathrm{hm}^{2} \cdot \mathrm{a}\right)$. 三山湿地的 TN、TP 主要来自岛上生活污水排放, 通过沉降、水生植物吸收、降解转化等过程实现对 TN、TP 的拦截. 自然沉降是净化氮、磷污染物的重要方式, 大量氮、磷物质沉积在底泥中, 底泥氮、磷是水生植物生长 的重要营养来源, 因其循环过程相对缓慢, 年内变化不大, 采用 2014 年 5 月 20 日的监测结果代表全年底泥 


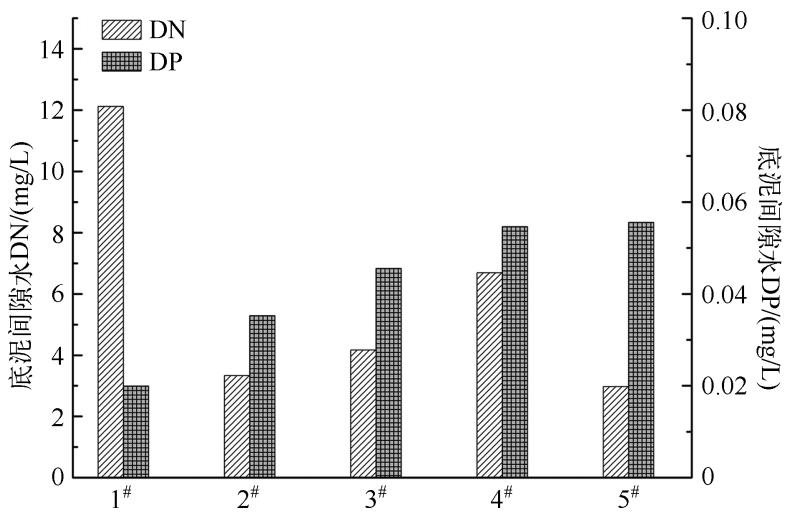

图 32014 年实测三山湿地底泥间隙水 DN 和 DP 的空间净化特征

Fig.3 Average dissolved nitrogen and phosphorus in Sanshan Wetland interstitial water in 2014
氮、磷含量状况, $6^{\#}$ 和 $7^{\#}$ 监测点因水体扰动 较大和位于深水区, 无法采集到底泥, 对 $1^{\#} \sim 5^{\#}$ 监测点的结果分析显示, $1^{\#}$ 监测点的 底泥间隙水 DN 浓度 $(12.1 \mathrm{mg} / \mathrm{L})$ 最高, 而 $\mathrm{DP}$ 浓度 $(0.02 \mathrm{mg} / \mathrm{L})$ 最低, 这与 $1^{\#}$ 监测点 附近分布的大量水生高等植物对 DP 吸收 能力较强有关, DN、DP 浓度沿 $2^{\#} \sim 4^{\#}$ 监测 点在空间分布上表现出明显的上升趋势 (图 3). 湿地建设中构建的生态围堰防浪区 有效避免了外围风浪冲刷, 为水体颗粒物 沉降创建了良好的环境, 底泥疏浚可提高 湿地氮、磷去除能力. 湿地内水生高等植物 能够吸收水体中 DN、DP, 降低水体 TN、TP 浓度,从而发挥水质净化作用.

本文只研究了在垂向上水体均匀情况 下湿地对 TN、TP 的净化效应. 但由于物质 来源组成、水动力环境、生物化学条件等不

同, 其含量可能在垂直分布变化上出现波动, 未来研究中还需要增加监测位点和不同深度水质, 对 TN、TP 在 水体不同深度条件下的分布对净化效果的影响还需要进一步探讨. 另外由于采样点数有限, 数据时间系列较 短, 通过统计学方法反映湿地氮、磷拦截作用存在较大的不确定性, 后期将在进一步监测的基础上开展统计 分析工作.

\section{3 三山湿地建设对水动力条件的影响}

三山湿地建设改变了湿地周围的水动力条件,进而影响水质净化效果.湿地建成对沿岸的太湖风浪起到 了一定的削弱作用, 表现为对湿地周围水体流向与流速的改变. 与无湿地分布情景下的模拟结果比较,湿地 建成后, 三山岛与泽山岛之间、三山岛西南部的水域水流速度显著减慢, 从 $6 \sim 8 \mathrm{~cm} / \mathrm{s}$ 下降到 $1 \mathrm{~cm} / \mathrm{s}$. 三山岛 南部湖湾区域没有明显的流动现象, 原先湖湾内部的小型环流消失. 在 $3.6 \mathrm{~m} / \mathrm{s}$ 东南风或西北风条件下, 湿 地范围内的水平流速均值从大于 $3 \mathrm{~cm} / \mathrm{s}$ 下降到 $0.44 \mathrm{~cm} / \mathrm{s}$.

水体流向变化能够减少氮、磷污染物和藻类等物质向三山岛南部沿岸区域输移通量, 降低藻类在沿岸 堆积的风险. 修筑堤岸和种植水生植物改变了湿地内部的水动力条件, 封闭的水域内水力停留时间延长, 在 氮、磷输人浓度不变的情况下, 湿地内部的悬浮物浓度降低, 同时水生植物抑制水动力因素对沉积物的扰 动, 抑制底泥再悬浮 ${ }^{\left[{ }^{30]}\right.}$, 降低了营养盐浓度, 抑制了藻类的生长, 为三山湿地的水生植物生长、水质改善提供 有利环境. 但水体流速的变小也为藻类生长提供稳定的环境, 为防止藻类的大量繁殖, 还需要加强控制水体 的营养盐浓度.

\section{4 结论}

1) 三山湿地可有效拦截来自太湖水体和三山岛上生活污水的氮、磷污染物, TN 拦截能力为 2723.56 $\mathrm{kg} /\left(\mathrm{hm}^{2} \cdot \mathrm{a}\right)$, TP 拦截能力为 $102.48 \mathrm{~kg} /\left(\mathrm{hm}^{2} \cdot \mathrm{a}\right) .2014$ 年度湿地对太湖水体 TN、TP 的拦截总量分别为 1.18 和 $0.12 \mathrm{t}$, 拦截率分别为 $25.2 \%$ 和 $56.5 \%$; 湿地对生活污水的 TN、TP 拦截总量分别为 439.77 和 $16.44 \mathrm{t}$, 拦截率分别为 $81.2 \%$ 和 $86.4 \%$.

2) 三山湿地对污染物的拦截净化方式主要为沉降和水生植物打捞/收割.2014 年输人的 TN、TP 通量分 别为 549.45 和 $19.40 \mathrm{t}$, 通过水生植物打捞/收割输出的约占 $3.8 \%$ 和 $23.3 \%$,其余输人湿地的 TN 、 TP 反映为 水体营养盐浓度变化量, 去向包括沉降进人底泥、降解转化、通过水体交换输出等.

3) 三山湿地的建设显著改变了周围水域的水动力条件.流向变化降低了氮、磷污染物和藻类在三山岛 南岸堆积的风险, 流速减小加快了污染物的沉降进程, 但同时也为藻类生长提供了稳定的环境, 需要加强控 
制水体的营养盐浓度以防止藻类大量繁殖, 合理恢复一定数量的湖泊湿地面积, 并通过底泥疏浚和打捞收 割水生植物, 可以充分发挥湿地净化入湖水质和湖泊水质、减少营养物质输人湖泊的作用.

致谢: 本研究野外调查得到苏州市东山镇三山村吴惠生书记、朱崇福先生大力支持,特此致谢.

\section{5 参考文献}

［1］赵其国，高俊峰. 中国湿地资源的生态功能及其分区. 中国生态农业学报，2007，15(1)：1-4.

[ 2 ] 任瑞丽, 刘茂松, 章杰明等. 过水性湖泊自净能力的动态变化. 生态学杂志, 2007, 26(8): 1222-1227.

[ 3 ] 陈诗越, 于兴修, 吴爱琴. 长江中下游湖泊富营养化过程的湖泊沉积记录. 生态环境, 2005, 14(4) : 526-529.

[ 4 ] 白军红, 邓 伟, 朱颜明. 湿地生物地球化学过程研究进展. 生态学杂志, 2002, 21(1) : 53-57.

[ 5 ] 吴春笃, 石 驰, 沈明霞等. 北固山湿地植物对氮磷元素吸收能力的研究. 生态环境, 2007, 16 (2) : 369-372.

[ 6 ] Wu H, Zhang J, Li P et al. Nutrient removal in constructed microcosm wetlands for treating polluted river water in northern China. Ecological Engineering, 2011, 37(4): 560-568.

[ 7 ] 彭世彰, 高焕芝, 张正良. 灌区沟塘湿地对稻田排水中氮磷的原位削减效果及机理研究. 水利学报, 2010, 41 (4) : 406-411.

[ 8 ] 李兆富, 刘红玉, 李恒鹏. 天目湖流域湿地对氮磷输出影响研究. 环境科学, 2012, 33(11) : 3753-3759.

[ 9 ］吴艳宏, 王苏民. 龙感湖小流域元素时空分布及湿地拦截功能探讨. 湿地科学, 2003, 1(1)：33-39.

[10］郗敏, 刘红玉, 吕宪国. 流域湿地水质净化功能研究进展. 水科学进展, 2006, 17(4) : 566-573.

[11] Kanyiginya V, Kansiime F, Kimwaga R et al. Assessment of nutrient retention by Natete wetland Kampala, Uganda. Physics and Chemistry of the Earth, Parts $A / B / C, 2010,35(13)$ : 657-664.

[12] 罗玲玲, 钟艳霞, 李小宇. 银川平原天然湖泊湿地生态系统水质净化能力探究. 生态经济, 2014, 30(9): 176-179.

[13] 徐德兰, 雷泽湘, 王洪君等. 太湖滨岸带芦苇区沉积物磷的特征. 湿地科学, 2007, 5(2): 133-139.

[14] 郑建伟, 关保华. 湖滨湿地氮磷的转化及其归趋研究进展. 南京信息工程大学学报: 自然科学版, 2009, 1(3): 238-242.

[15] 程文辉, 王船海, 朱 琰. 太湖流域模型. 南京: 河海大学出版社, 2006: 117.

[16] Huang J, Gao J, Georg H. Integrating three lake models into a phytoplankton prediction system for Lake Taihu (Taihu PPS) with Python. Journal of Hydroinformatics, 2012, 14(2) : 523-534.

[17] Huang J, Gao J, Hörmann G. Hydrodynamic-phytoplankton model for short-term forecasts of phytoplankton in Lake Taihu, China. Limnologica, 2012, 42(1): 7-18.

[18] Huang J, Gao J, Liu J et al. State and parameter update of a hydrodynamic-phytoplankton model using ensemble Kalman filter. Ecological Modelling, 2013, 263: 81-91.

[19] Hu W, Jørgensen SE, Zhang F. A vertical-compressed three-dimensional ecological model inLake Taihu, China. Ecological Modelling, 2006, 190(3) : 367-398.

[20] Huang J, Gao J, Zhang Y et al. Modeling impacts of water transfers on alleviation of phytoplankton aggregation in Lake Taihu. Journal of Hydroinformatics, 2014, 17( 1) : 149-162.

[21] 翟淑华, 韩 涛, 陈 方. 基于质量平衡的太湖氮、磷自净能力计算. 湖泊科学, 2014, 26(2)：185-190. DOI 10. 18307/2014. 0203.

[22] 李一平, 逢 勇, 刘兴平等. 太湖波浪数值模拟. 湖泊科学, 2008, 20(1)：117-122. DOI 10. 18307/2008. 0118.

[23] 许遐祯, 陶蓉茵, 赵巧华等. 大型浅水湖泊太湖波浪特征及其对风场的敏感性分析. 湖泊科学, 2013, 25(1): 5664. DOI 10. 18307/2013. 0108.

[24] 万晓红, 周怀东, 刘玲花等. 白洋淀湖泊湿地中氮素分布的初步研究. 水土保持学报, 2008, 22(2)：166-169.

[25] Vymazal J. Removal of nutrients in various types of constructed wetlands. Science of the Total Environment, 2007, 380 (1): $48-65$.

[26］刘 佳, 张 奇, 高海鹰. 模拟降解去除人工湿地营养物. 环境污染与防治, 2006, 28(9) : 698-702.

[27] Zhao G, Hörmann G, Fohrer N et al. Development and application of a nitrogen simulation model in a data scarce catchment in South China. Agricultural Water Management, 2011, 98(4): 619-631.

[28] Zhao G, Hörmann G, Fohrer N et al. Application of a nutrient model for sediment yield and phosphorus load estimation in an agricultural catchment in south China. Fresenius Environmental Bulletin, 2012, 21(7) : 1894-1904.

[29] 吴爱平, 吴世凯, 倪乐意. 长江中游浅水湖泊水生植物氮磷含量与水柱营养的关系. 水生生物学报, 2005, 29 (4) : 406-412.

[30］王 忖, 王 超. 含挺水植物和沉水植物水流紊动特性. 水科学进展, 2010, 21(6) : 816-821. 